\title{
Glenoid Fossa Morphology, a Study in Dry Adult Human Scapula
}

\author{
Dr. Durgesh Singh ${ }^{1}$, Dr. Kalpana Purohit ${ }^{2}$, Dr. Vipul Kant Singh $^{3}$, \\ Dr. Shashi Prabha Singh ${ }^{4}$, Dr. Ankita Purohit ${ }^{5}$. \\ $1 \& 4$ Tutor Shekh-ul Hind Maulana Mahmud Hasan Medical college,Saharanpur, Uttar Pradesh. \\ $2 \& 3$ Assistant Professor, Hind Institute Of Medical Sciences, Mau, Ataria, Sitapur, Uttar Pradesh. \\ 5 Tutor Cum PG Student SCB Medical College, Cuttack, Odisha
}

\begin{abstract}
Integrity of the glenoid cavity of scapula is needed for free movement of the upper limb. It is commonly affected by osteoarthritis and trauma. Arthroplasty which is the mode of treatment requires a proper and perfect prosthesis for better function of the joint. The measurements of glenoid cavity vary in different races and locality. The present study is to observe the dimensions of glenoid cavity of scapula in the state of Uttar Pradesh.
\end{abstract}

Keywords: Glenoid cavity, Dimensions, Arthroplasty, Prosthesis

\section{Introduction}

The shoulder joint is a ball and socket variety of synovial joint. It has more mobility then stability. The lateral angle of the scapula is called the head of the scapula. It is also called glenoid fossa or glenoid cavity of scapula. The head of the scapula, is connected to the body by the neck of scapula [1]. The small glenoid fossa articulates with the larger head of the humerus making it a inherent instable joint. The stability of the humeral head on the glenoid fossa is provided by the musculotendinous cuff. Fracture of the glenoid rim is usually associated with dislocation of the glenohumeral joint [11]. The inherent instability of the joint makes the glenoid surgery, the most difficult procedure for the treatment of glenohumeral arthritis [2,3]. The shape of the glenoid cavity is variable. Anatomical parameters like shape, height, width, articular surface area and inclination of the glenoid cavity are relevant to design the prosthesis [9].

\section{Materials And Methods}

The study was carried out in the Department of Anatomy, Hind Institute of Medical Sciences, Mau, Ataria, Sitapur. One hundred and six adult dry unpaired scapulae were included, out of which 61 were of right side and 45 were of left side. Age and sex of the bones was not considered. The superior-inferior and the anterior-posterior diameters of glenoid fossa were measured using the Vernier sliding caliper. The superiorinferior glenoid diameter was taken from the most prominent point of the supraglenoid tubercle to the inferior point on the glenoid margin. The anterior-posterior glenoid diameter was taken from the maximum breadth of the articular margin of the glenoid cavity perpendicular to the superior-inferior diameter of glenoid cavity. The shape of the glenoid fossa was also noted

\section{Results}

The mean superior - inferior (SI) diameter of the glenoid fossa on the right side scapulae was $3.70 \pm$ 0.30 and left scapulae was $3.61 \pm 0.43$ centimeters. The mean anterior - posterior (AP) diameter of the glenoid fossa on the right scapulae was $2.45 \pm 0.27$ and left scapulae was $2.46 \pm 0.23$ centimeters [table 1]

In left side, out of 45 scapulae, the pear shaped glenoid fossa was found in $8(17.78 \%)$, the oval shape was 23 $(51.11 \%)$, and the coma shape was $14(31.11 \%)$. In right side, out of 61 scapulae, the pear shaped glenoid fossa was found in $4(6.56 \%)$, the oval shape was $36(59.02 \%)$, the coma shape was $21(34.43 \%)$. Out of total 106 scapulae, the pear shaped glenoid fossa was found in 12,the oval shape was 59 , the coma shape was 35 [table 2].

\section{Discussion}

The knowledge of shape and size of the glenoid fossa are required for successful shoulder arthroplasty and minimize failure rates in the surgery [11]. The shape of the glenoid cavity can be of three types. When a distinct notch is present in the anterior margin of the glenoid cavity, the shape of the glenoid cavity can be described as inverted comma-shaped. If an indistinct notch is present it is described as pear-shaped. In absence of the notch, the cavity is oval shaped $[4,6]$. The shoulder joint is the most frequently dislocated joint in the body. Dislocations with fractures of the glenoid are also quite common in trauma [7]. The anatomical basis and variations of shape and size of glenoid cavity of scapula is of fundamental importance in understanding of rotator cuff disease, shoulder dislocation and to decide the proper size of the glenoid component in the shoulder 
arthroplasty [8]. In this study The mean superior - inferior (SI) diameter of the glenoid fossa on the right side scapulae was $3.70 \pm 0.30$ and left scapulae was $3.61 \pm 0.43$ centimeters. The mean anterior - posterior (AP) diameter of the glenoid fossa on the right scapulae was $2.45 \pm 0.27$ and left scapulae was $2.46 \pm 0.23$ centimeters. The diameters are similar to the study by Von Schroeder et al. \& they are higher than the study by Moosa Shajiya Sarwar(2015), Mamtha et al(2011), Hina B Rajput(2012), and lower than what was observed by Iannotti et al (1992)[table 3]. The most common shape found was the oval shape, which was (59\%) \& the pear shaped were found least(12\%). In the studies by Hina B Rajput(2012), Moosa Shajiya Sarwar(2015), Gamal Hamed El-Sayed Hassanein(2015) most common shape found was pear shape.

\section{Conclusion}

The mean superior - inferior (SI) diameter of the glenoid fossa on the right side scapulae was $3.70 \pm$ 0.30 and left scapulae was $3.61 \pm 0.43$ centimeters. The standard available smallest glenoid component in the market is 4 centimeters[8]. The diameter in this study is close to the size of prosthesis available. The most frequent shape of scapula in this study is oval.

\section{References}

[1]. Gray's Anatomy, The Anatomical Basis of Clinical Practice.40th ed., Churchill Livingstone, 2008; $791-822$.

[2]. Schrumpf M, Maak T, Hammoud S, Craig EV. The glenoid in total shoulder arthroplasty. Curr Rev Musculoskelet Med, 2011; 4:191-199.

[3]. Rajput HB, Vyas KK, Shroff BD. A Study of Morphological Patterns of Glenoid Cavity of Scapula. Natl J Med Res, 2012; 2(4):504-507.

[4]. Gamal Hamed El-Sayed Hassanein. morphometry of glenoid fossa in adult Egyptian scapulae, int j anat res 2015; vol 3(2):1138-42.

[5]. Polguj M, Jêdrzejewski KS, Podgórski M, Topol M. Correlation between morphometry of the suprascapular notch and anthropometric measurements of the scapula. Folia Morphol, 2011; 70:109-115

[6]. Prescher A and Klumpen T. The glenoid notch and its relation to the shape of the glenoid cavity of the scapula. J Anat, 1997;190:457-460.

[7]. Mamatha T, Pai SR, Murlimanju BV, Kalthur SG, Pai MM, Kumar B. Morphology of glenoid cavity. Online J health Allied Scs. 10(3), 2011, 7

[8]. Rajput HB, Vyas KK, Shroff BD. A study of morphological patterns of the glenoid cavity of scapula National J of Medical Research, 2012; 2(4) : 504-507.

[9]. Gosavi S.N., Dr. Jadhav S. D., Dr. Garud R.S. Morphometric study of Scapular glenoid cavity in Indian population, IOSR-JDMS, Ver. III (Sep. 2014),Volume 13, Issue 9 PP 67-69

[10]. Moosa Shajiya Sarwar, Diwan C V, Abdul Rafe,et al, A morphometric study of glenoid cavity of adult human scapula, International Journal of Recent Trends in Science And Technology, 2015; Volume 15, Issue 3, pp 486-490.

[11]. Ajay Kumar Mahto, Saif Omar, Dimensions of Glenoid Fossa of Scapula: Implications in the Biomechanics of an Implant

[12]. Design, International Journal of Scientific Study, July 2015; Vol 3, Issue 4:146-148

[13]. von Schroeder HP, Kuiper SD, Botte MJ. Osseous anatomy of the scapula. ClinOrthopRelat Res, 2001; 383:131-139.

[14]. Iannotti JP, Gabriel JP, Schneck SL, Evans BG, Misra S. The normal glenohumeral relationships. An anatomical study of one hundred and forty shoulders.J Bone Joint Surg Am 1992; 74:491-500.

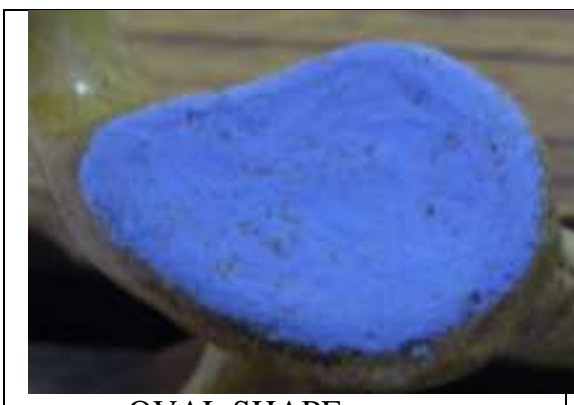

OVAL SHAPE

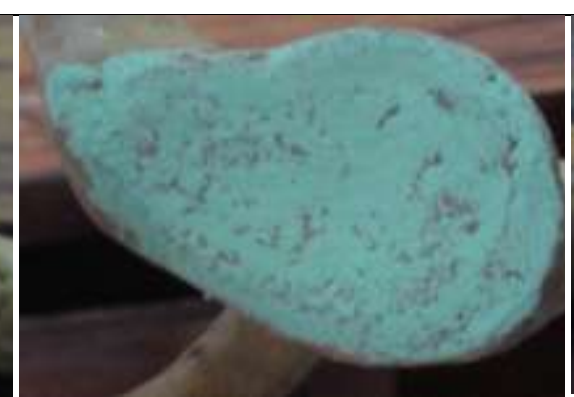

PEAR SHAPE

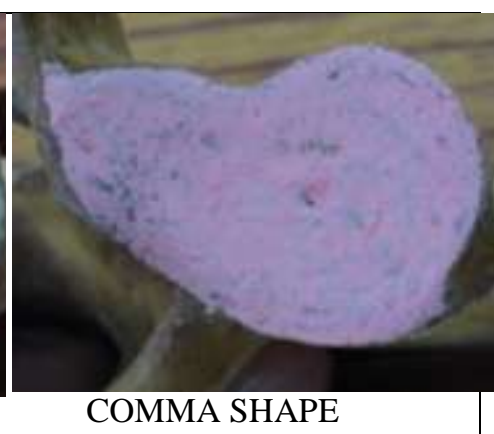

COMMA SHAPE

Table 1 Mean S-I, A-P diameter

\begin{tabular}{|l|l|l|l|l|l|}
\hline \multicolumn{2}{|l|}{ Variable } & \multicolumn{2}{|l|}{$\begin{array}{l}\text { SUPERIOR } \\
\text { INFERIOR }\end{array}$} & \multicolumn{2}{l|}{$\begin{array}{l}\text { ANTERIOR } \\
\text { POSTERIOR }\end{array}$} \\
\hline & & Mean & $\begin{array}{l}\text { Std. } \\
\text { Deviation }\end{array}$ & Mean & $\begin{array}{l}\text { Std. } \\
\text { Deviation }\end{array}$ \\
\hline LEFT & 45 & 3.61 & 0.43 & 2.46 & 0.23 \\
\hline RIGHT & 61 & 3.70 & 0.30 & 2.45 & 0.27 \\
\hline
\end{tabular}

Table 2 Percentage of different shapes

\begin{tabular}{|l|l|l|l|l|}
\hline & OVAL & COMA & PEAR & N \\
\hline Left & 51.11 & 31.11 & 17.78 & 45 \\
\hline Right & 59.02 & 34.43 & 6.56 & 61 \\
\hline Total & 59 & 35 & 12 & 106 \\
\hline
\end{tabular}


Table 3 Comparison of Superior-Inferior and Anterior-Posterior-1 diameters in different studies

\begin{tabular}{|c|c|c|c|}
\hline Study & $\begin{array}{l}\text { Side } \\
\text { scapula }\end{array}$ & S-I diameter & A-P diameter \\
\hline $\begin{array}{ll}\text { Moosa } & \text { Shajiya } \\
\text { Sarwar(2015) } & \\
\end{array}$ & \multirow[t]{4}{*}{ Left } & $34.53 \pm 3.21 \mathrm{~mm}$ & $23.64 \pm 2.37 \mathrm{~mm}$ \\
\hline Mamtha et al(2011) & & $33.92 \pm 2.87 \mathrm{~mm}$ & $23.02 \pm 2.30 \mathrm{~mm}$ \\
\hline Hina B Rajput(2012) & & $34.43+3.21$ & $22.92+2.80$ \\
\hline Present study & & $3.61 \pm 0.43 \mathrm{~cm}$ & $2.46 \pm 0.23 \mathrm{~cm}$ \\
\hline $\begin{array}{ll}\text { Moosa } & \text { Shajiya } \\
\text { Sarwar(2015 } & \\
\end{array}$ & \multirow{4}{*}{ Right } & $35.22 \pm 3.26 \mathrm{~mm}$ & $23.95 \pm 2.78 \mathrm{~mm}$ \\
\hline Mamtha et al(2011) & & $33.67 \pm 2.82 \mathrm{~mm}$ & $23.35 \pm 2.04 \mathrm{~mm}$ \\
\hline Hina B Rajput(2012) & & $34.76+3$ & $23.31+3.0$ \\
\hline Present study & & $3.70 \pm 0.30 \mathrm{~cm}$ & $2.45 \pm 0.27 \mathrm{~cm}$ \\
\hline $\begin{array}{l}\text { Von Schroeder } \text { et al } \\
\text { (2001) }\end{array}$ & & $36 \pm 4 \mathrm{~mm}$ & $28.6 \pm 3.3 \mathrm{~mm}$ \\
\hline Mallon et al (1992) & & $35 \pm 4.1 \mathrm{~mm}$ & $24 \pm 3.3 \mathrm{~mm}$ \\
\hline Iannotti et al (1992) & & $39 \pm 3.5 \mathrm{~mm}$ & $29 \pm 3.2 \mathrm{~mm}$ \\
\hline
\end{tabular}

